Revista de la Escuela de Ciencias de la Educación. 2022, Año 18 1(17). 1-17 Enero a junio. Nicastro, S. Las instituciones y las organizaciones educativas como objeto de análisis y producción de conocimiento situado. Notas para pensar la formación.

\title{
LAS INSTITUCIONES Y LAS ORGANIZACIONES EDUCATIVAS COMO OBJETO DE ANÁLISIS Y PRODUCCIÓNDE CONOCIMIENTO SITUADO. NOTAS PARA PENSAR LA FORMACIÓN
}

\author{
INSTITUTIONS AND EDUCATIONAL ORGANIZATIONS AS OBJECT OF ANALYSIS \\ AND PRODUCTION OF LOCATED KNOWLEDGE. NOTES TO THINK ABOUT \\ TRAINING
}

Sandra Nicastro

Universidad de Buenos Aires. Argentina nicastrosandra@hotmail.com

Recibido: 28 de julio 2021

Aprobado: 16 de septiembre de 2021 Publicado: 31 de diciembre de 2021

Cita sugerida: Nicastro, S. (2022). Las instituciones y las organizaciones educativas como objeto de análisis y producción de conocimiento situado. Notas para pensar la formación. Revista de la Escuela de Ciencias de la Educación, 1(17)1-17.

\section{RESUMEN}

En este trabajo nos interesa reflexionar acerca de nuestro lugar como formadorxs que, atravesadxs y conmovidxs ante los escenarios actuales, reflexionamos acerca del abordaje de las instituciones y las organizaciones educativas como objetos de análisis y producción de conocimiento situado. Para ello proponemos un trabajo de elucidación permanente sobre nuestra posición implicada, como una oportunidad para pensar a otrxs y con otrxs, los efectos de dispersión que esos contextos portan y tienen sobre los procesos de subjetivación y de pensamiento colectivos, y entendiendo que se trata de un lugar que se construye en determinados tiempos y espacios institucionales, sociales, históricos, políticos.

Nuestra reflexión se apoya en los trabajos de algunxs representantes del análisis institucional francés, latinoamericano y argentino que reconocieron que al pensar la posición que asumimos frente al análisis es importante tener en cuenta una serie de cuestiones relativas a la relación de las instituciones, las 
Revista de la Escuela de Ciencias de la Educación. 2022, Año 18 1(17). 1-17 Enero a junio. Nicastro, S. Las instituciones y las organizaciones educativas como objeto de análisis y producción de conocimiento situado. Notas para pensar la formación.

organizaciones, los grupos y los sujetos desde perspectivas situadas y contextualizadas.

Palabras clave: Institución - Organización - Posición - Implicación Formación.

\section{ABSTRACT}

In this article we are interested in reflecting about our place as educators, that traversed and moved by the actual scenarios, we study the educational institutions and organizations as objects of analysis and production of situated knowledge. To achieve that, we put forward a permanent elucidation work on our implied position, as an opportunity to think about and with others the effects of the dispersion that those contexts carry and have over the subjectivation processes and collective thinking, considering that that position is built upon specific institutional social, historical and political time and spaces.

Our reflection is supported on the work of some of the representatives of the French, Latin- American and Argentinian institutional analysis who acknowledged that when we think about the position, we assume towards the analysis it is important to pay attention to a series of matters related to the relation between institutions, organizations, groups and subjects, from situated and contextualized perspectives.

Keywords: Institution - Organization - Position - Implication - Training.

\section{INTRODUCCIÓN}

El verdadero viaje de descubrimiento no consiste en buscar nuevos caminos si no en tener nuevos ojos. (Proust, 1967, s/p)

Nos abocaremos en este escrito a pensar las instituciones y las organizaciones educativas, haciendo de ellas un objeto de estudio, análisis y producción de conocimiento situado, lo que en simultáneo implica un proceso de desentrañamiento, que en sí mismo es inagotable. En simultáneo, advertir nuestro lugar allí, desde una posición implicada, en el marco de un recorrido que siempre nos transforma.

En primer lugar, nos interesa reconocer que se trata de un tema sobre el cual volvemos una y otra vez, a riesgo de repetir algunas ideas, pero convencidxs de que siempre es una oportunidad para pensarnos como formadorxs. Y sabiendo en simultáneo, que se trata de un pensamiento que está en obra de modo permanente por lo cual ¿es repetición o es un revisitar que conlleva invención?

Nuestra reflexión se apoya en los trabajos de algunxs representantes del análisis institucional francés, latinoamericano y argentino que reconocieron que al pensar la posición queasumimos frente al análisis es importante tener en cuenta una serie de cuestiones relativas a la relación de las instituciones, las organizaciones, los grupos y los sujetos en la producción de conocimiento.

Nos interesa en este momento problematizar los propósitos que nos 
Revista de la Escuela de Ciencias de la Educación. 2022, Año 18 1(17). 1-17 Enero a junio. Nicastro, S. Las instituciones y las organizaciones educativas como objeto de análisis y producción de conocimiento situado. Notas para pensar la formación.

planteamos como formadorxs en los espacios en los que nos encontramos una y otra vez, ya sea los de la formación propiamente dicha, como también los de asesoramiento y/o coordinación, en la indagación, búsqueda y recopilación de información, también en la delimitación de espacios de trabajo con otrxs, en la definición de encuadres y dispositivos de intervención.

Podríamos decir que estas mismas acciones definen aquellos propósitos, pero, avanzando un poco más y apoyándonos en algunos aportes del análisis institucional, entendemos necesario hacer foco tanto en el campo de intervención como en el del análisis quese definen como objeto. Para ello nos centraremos en las instituciones, las organizaciones educativas y sus relaciones, los modos de transmisión y traducción y los diferentes grados de conflictividad, tensión y controversia inherentes al fenómeno que nos proponemos estudiar, reconociendo como supuestos de base la centralidad de la cuestión política y los modos de producción socio históricos.

Tal como lo señala Lourau (1975), el estudio de las instituciones y las organizaciones desde la perspectiva institucional discute una idea de teoría como construcción pura y acabada ya que

el análisis institucional no pretende producir un super saber clandestino y misterioso, más completo y más verdadero que los otros saberes... Aspira a producir una nueva relación con el saber que implique una conciencia del nosaber que siempre determina nuestra acción (p. 19)

Siguiendo los aportes de Castoriadis (1999) podemos decir que este acercamiento conlleva un objetivo de elucidación cuando se refiere al trabajo que hacemos al pensar lo que hacemos y saber lo que pensamos. En sus palabras "ese hacer pensante es tal, por excelencia, cuando se trata del pensamiento político, y de la elucidación de lo social-histórico que implica" (p.11)

En este marco desde diferentes aportes la elucidación supone un pensamiento que interpela los supuestos en los que se apoya, interroga lo implícito y lo tácito, reconociendo la complejidad de la cuestión cuando se trata de un tipo de pensamiento que se sostiene en la diferencia, la conflictividad, la tensión y la interpelación en tanto condiciones de entendimiento y de producción de conocimiento.

Lejos está de este planteo suponer que se trata de un movimiento en el cual se da un pasaje de lo desconocido a lo conocido, de lo inconsciente a lo consciente, de lo no manifiesto alo manifiesto, como es el caso de quienes suponen la existencia de una verdad que debe ser vislumbrada, descubierta y abarcada. En parte por esto, el estudio de las instituciones y las organizaciones educativas supone un tratamiento en profundidad de los marcos teóricos referenciales y de los encuadres y herramientas de los análisis ligados al trabajo de formación, asesoramiento y/o coordinación.

A partir de aquí, nos interesa preguntarnos por determinados fenómenos ligados a entender la dinámica de las organizaciones educativas, de una clase escolar o un grupo determinado, a dilucidar las relaciones intrínsecas entre los 
Revista de la Escuela de Ciencias de la Educación. 2022, Año 18 1(17). 1-17 Enero a junio. Nicastro, S. Las instituciones y las organizaciones educativas como objeto de análisis y producción de conocimiento situado. Notas para pensar la formación.

diferentes componentes de una escena educativa, a comprender la lógica vincular entre Ixs sujetos, su trabajo y los otros, a producir conjeturas acerca de las producciones institucionales en su dimensión material, culturaly simbólica, a reconocer los atravesamientos de diferentes ámbitos, desde los más próximos como pueden ser Ixs pares, las familias, la comunidad, a lo social, lo territorial, lo político, entre otros.

Se trata de cuestiones nodales que se plantean más de una vez en los espacios de formación, desde diferentes instancias, perspectivas y disciplinas y en este momento abordaremos desde un análisis de tipo multirreferencial y un enfoque clínico.

Al decir de Ardoino (1993) el análisis multirreferencial supone una lectura plural realizada, sobre una cuestión, desde diferentes ángulos, atenta de no escindir los contextos en los cuales se inscribe, en tanto contextos de producción, discusión y reflexión, ni de las operaciones analíticas que allí se despliegan. Si así no fuera, abonaríamos la idea de un objeto de conocimiento independiente del sujeto y por lo tanto en términos de este autor, transparente y objetivo, y de un proceso de análisis que separa lo simple de lo complejo, la parte del todo, como si solo se tratara de encontrar un método eficaz.

Reconocemos que el trabajo como formadorxs es un espacio privilegiado donde hacer lugar a esta lectura plural. Por ejemplo, cuando nos identificamos con otrxs, resonamos desde diferentes lecturas, aprendemos problematizando, interrogamos lo que naturalizamos, reconociendo y también disputando el límite que nos imponen las mismas instituciones que nos atraviesan y configuran.

Con respecto al enfoque clínico, más allá de reconocer que se trata de quien, como dice Enriquez (1993) "está, de cierta manera, al pie de la cama, ayudando a cada uno a encontrar su propio camino" (s/p), nos parece fundamental advertir, siguiendo sus hipótesis, que se puede incurrir en las mismas tendencias que se critican a las posiciones objetivantes, al creer que este enfoque es garantía de no caer en situaciones paradojales o francamente alejadas de los propósitos iniciales. Por eso dirá este autor "los clínicos deben ser invitados a la modestia, porque pueden, así como los partidarios de las aproximaciones objetivas, reificar el mundo y los seres, aun cuando su proyecto sea naturalmente de otra naturaleza" (pp.30 -31).

Conocer, abordar fenómenos institucionales será un propósito ambicioso por la naturaleza de su objeto (Castoriadis, 2006), por la complejidad que acarrea la construcción de los marcos teóricos (Garay, 1996) y por las dificultades que se oponen a un tipo de pensamientocomo al que se aspira (Kaës, 1989).

Con respecto a la primera cuestión, relativa a entender lo ambicioso del propósito que nos planteamos, Castoriadis (2006) advierte que tiene que ver con nuestra posición respecto de las instituciones y las organizaciones en tanto sujetos que las habitamos, que vivimos en ellas, que nos alojan. Son nuestros ámbitos naturales, lugares donde llegamos al mundo, trabajamos, nos reconocemos y conformamos como colectivo. Para este autor, la intención de avanzar en el conocimiento acerca de las instituciones se ve confrontada con el hecho de que estamos allí, que nos constituyen y preexisten, las herramientas para explorarlas y adentrarnos en sus lógicas, son parte de las mismas. Una 
Revista de la Escuela de Ciencias de la Educación. 2022, Año 18 1(17). 1-17 Enero a junio. Nicastro, S. Las instituciones y las organizaciones educativas como objeto de análisis y producción de conocimiento situado. Notas para pensar la formación.

palabra clave que utilizará para sostener sus reflexiones será la de "ruptura", en el sentido de marcar un punto de inflexión que ponga en cuestión un vínculo signado por la dependencia, abriendo a la oportunidad de la crítica y el conocimiento.

Esta ruptura implica que estos mismos individuos que fueron fabricados por su sociedad, que constituyen los fragmentos ambulantes de ella, pudieron transformarse esencialmente, pudieron crear para sí los recursos capaces de cuestionar las instituciones de la sociedad, que los habían formado a ellos mismos -hecho acompañado, evidentemente, por un cambio esencial de todo el campo social instituido-. Esto se traduce, a la vez, en el nacimiento de un espacio político público y en la creación de (...) la interrogación permanente (2006, p.117).

Siguiendo su pensamiento, Fernández, A. M. (2014) apela, recuperando las ideas centrarles de ese autor sobre el trabajo de elucidación, a la creación de nuevas condiciones de entendimiento. En este sentido sostiene que:

Se vuelve invisible no lo que está oculto sino lo que está a la vista, pero no puede dársele entidad porque no responde a los modelos de pensamiento y acción existentes; en esos casos estos modelos, agotados pero vigentes, operan como únicas categorías de pensamiento ( $\mathrm{s} / \mathrm{p})$.

En los tiempos que corren la provisoriedad, la incertidumbre, la alteración del andamiaje subjetivo, cultural, político y por todo ello, institucional, se presentan como condiciones de nuestras vidas y por lo tanto de nuestro trabajo. Desde aquí, y siguiendo las hipótesis anteriores, entendemos que, al pensar las instituciones, las organizaciones educativas y nosotrxs allí es necesario reconocer los efectos de dispersión que esos rasgos portan y tienen sobre nosotrxs, en los procesos de subjetivación y de pensamiento, a la vez de entender el carácter sostenido y, a veces, abrumador del peso de lo instituido por estabilizar y encauzar lo que acontece.

Desde la mirada de Garay (1996), centrada en el análisis institucional, existen una serie de obstáculos para pensar y analizar las instituciones derivados del entramado heterogéneo de teorías, categorías y supuestos que remiten a diferentes disciplinas y que requieren alta vigilancia en su transposición. No se trata de un corpus determinado de conocimientos y saberes, acotado y circunscripto en el sentido de la identidad de una disciplina, sino que como señala esa autora:

La fuente de conceptos y supuestos remite a una diversidad de campos de las ciencias sociales y humanas y exige un esfuerzo adicional de selección, de rigor en su aplicación para analizar fenómenos y procesos (institucionales) que no les dieron origen (p. 128)

Un ejemplo de lo que estamos diciendo se hace evidente en una crítica que le hace Lourau a Ardoino, cuando advierte que este último, define lo 
Revista de la Escuela de Ciencias de la Educación. 2022, Año 18 1(17). 1-17 Enero a junio. Nicastro, S. Las instituciones y las organizaciones educativas como objeto de análisis y producción de conocimiento situado. Notas para pensar la formación.

institucional como un nivel, entre otros, necesario para entender el campo de lo social, supuesto que tiende, según Lourau, a la fragmentación de la institución como objeto.

La respuesta que esgrime Ardoino a esa crítica pone en evidencia la idea de obstáculo a la que nos estamos refiriendo, cuando dice que en tanto "las instituciones están en todas partes y en ninguna", en el intento de espacializar, de esquematizar su presencia llegó a la idea de nivel. Algo así como que esa idea, operó como un artilugio discursivo para dar algún tipo de referencialidad y ayudar en su comprensión. Es decir que, como dice Garay (1996), el obstáculo se configuró en el entramado de conceptos y supuestos.

Respecto de las dificultades, Kaës (1989) señalará, en diálogo con la reflexión de Castoriadis (1989), que pensar las instituciones implica admitir la intervención insoslayable de los aspectos subjetivos, emocionales, de cada unx y con otrxs en el trabajo colectivo de pensar que, para este autor

cumple una de las funciones capitales de las instituciones, consistente en proporcionar representaciones comunes y matrices identificatorias: proporcionar un estatuto a las relaciones de la parte y el conjunto, vincular los estados no integrados, proponer objetos de pensamiento que tienen sentido para lo sujetos a los cuales está destinada la representación y que generan pensamientos sobre el pasado, el presente y el porvenir, indicar los límites y las transgresiones, asegurar la identidad, dramatizar los movimientos pulsionales (p. 18).

A partir de lo dicho, al pensar y analizar determinadas situaciones y fenómenos, y de cara a la relación entre Ixs sujetos y las instituciones que nos atraviesan y las organizaciones educativas que habitamos, reconocemos que estamos allí y advertimos que portamos y nos sostenemos permanentemente en un conjunto de saberes, juicios, concepciones, experiencias que conforman nuestro marco referencial.

Desde aquí avanzaremos en una cuestión que consideramos central que tiene que ver con nuestra posición e implicación, en tanto formadorxs, en el abordaje de diferentes fenómenosy situaciones institucionales, en su análisis y tratamiento y en la producción de determinado conocimiento situado.

\section{DESARROLLO}

\section{El trabajo de formar: una posición implicada}

Volvamos a las prácticas de indagación, exploración, abordaje e intervención propias de los espacios de formación, asesoramiento y/o coordinación y escuchemos algunas preguntas que se reiteran, más de una vez, como un modo de acercarnos a quienes allí se encuentran.

Por ejemplo, Ixs estudiantes en formación, en algunos de los espacios de prácticas, que se preguntan qué observar y cómo, qué registrar y cómo, qué preguntar, cuándo y cómo. O Ixs colegas asesorxs cuando se preguntan, al realizar un diagnóstico, qué hacer con la información producida para transformarla en objeto de trabajo, más allá de la conocida devolución. O Ixs 
Revista de la Escuela de Ciencias de la Educación. 2022, Año 18 1(17). 1-17 Enero a junio. Nicastro, S. Las instituciones y las organizaciones educativas como objeto de análisis y producción de conocimiento situado. Notas para pensar la formación.

formadores, al lidiar con las expectativas cruzadas sobre su trabajo y entonces, qué lugar asumir, cómo hacerlo y sostenerlo, entre tantos otros ejemplos.

En todos los casos, se trata de preguntas pertinentes y esperables en espacios donde debatimos más de una vez, si se trata de una cuestión de método, de marco teórico, de enfoque de una disciplina, entre otros asuntos. Preguntas que no se saldan, no se contestan de una vez y para siempre, porque van más allá de decir qué o cómo hacer. Preguntas que tienen respuestas provisorias y no por ello son expresión de déficit o dificultad, sino en más de un caso, paradojalmente, garantía de escucha situada y contextualizada.

En este momento más que responder a aquellas preguntas acerca del qué y del cómo y a propósito de problematizar con ellas los contextos en los cuales se inscriben, nos abocaremos a pensar en nuestra posición frente al trabajo de análisis, entendiendo ante todo que se trata de un lugar que se construye en la relación con otrxs, en determinados tiempos y espacios institucionales, sociales, históricos, políticos.

¿Por qué esta decisión? Porque entendemos que es una condición necesaria ante cualquier intento de avanzar en el abordaje de aquellas preguntas y/o la elaboración de algunas respuestas. En simultáneo, será posible definir criterios que orienten la acción que, por lo que acabamos de decir, serán revisados una y otra vez. Cuando esto no ocurre, uno de los riesgos, es que el trabajo se instrumentalice, se protocolice, como si solo de eso se tratara. En realidad, y casi al revés de lo esperado, el diseño de un instrumento, el aprendizaje de una técnica, se sostienen en las definiciones y supuestos que conforman, tal como lo señala Lourau (1979), el campo de intervención y de análisis.

Preocupadxs por hacer foco en nuestra posición, lo primero que vamos a señalar es que no se trata de una posición ingenua o desafectada respecto del tema o la situación que se tiene por delante. Estamos "afectados" como decía Ulloa (1995), en tanto el estar afectado tiene de ser "afecto", al trabajo de formar en nuestro caso, y tiene de "afectado" por estar empáticamente vinculadxs con el contexto en el cual vivimos.

Tampoco es una posición que supone, como venimos diciendo, contar con respuestas acabadas y saber, entender o comprender de qué se trata en cada caso, anticipadamente o en un tiempo ya, como si todo fuera conocido, obvio o del orden de lo ya sabido.

En esta línea, reconocemos los aportes de Oury, J. (2020) cuando discute la idea de "va de suyo" como si, desde una posición de cierta certidumbre, no hiciera falta explicar, profundizar, indagar y volver a pensar determinadas cuestiones. Dirá este autor, "no va de suyo", contraponiéndose a aquella afirmación y así, hacer lugar al análisis, a la reflexión, a la búsqueda.

A propósito de estas reflexiones recordamos el relato que Jackson (1999) desarrolla en un capítulo de su texto "Enseñanzas implícitas" sobre la experiencia como observador en un salón de clases. Allí cuenta que una de sus primeras 
Revista de la Escuela de Ciencias de la Educación. 2022, Año 18 1(17). 1-17 Enero a junio. Nicastro, S. Las instituciones y las organizaciones educativas como objeto de análisis y producción de conocimiento situado. Notas para pensar la formación.

impresiones fue que le llamó la atención cierto "desorden" en la clase, cuestión que lo llevó a preguntarse inmediatamente por su posición allí. Dice así

quería saber cómo encajaba yo en el proceso, cómo encajaban mis reacciones e intuiciones personales tales como el vago sentimiento de incomodidad y confusión que me había provocado el desorden que imperaba en el salón (p.70).

A lo largo del texto, señala enfáticamente que alguna postura que se llame a sí misma científica y objetiva respecto de la enseñanza podría apelar a posiciones neutrales y miradas imparciales. Sin embargo, lo que él estaba proponiendo y nosotros compartiendo, no iba por ese camino, sino por miradas cordiales sobre Ixs otrxs, una manera de observar que promueve acercamiento, dando por descontada su implicación.

En síntesis, coincidimos con las posturas de los autores presentados porque asumimos que nada de lo que ocurre en una experiencia educativa va de suyo, ni en la escuela pre pandemia ni en la escuela actual, ya que en todos los casos formar parte tiene efectos ineludibles e inéditos sobre la configuración de las posiciones institucionales.

Atentos al tiempo que estamos atravesando, el grado de excepcionalidad o de "excepción excepcional", en palabras de Boaventura de Souza Santos (2020), conmueve los diferentes ámbitos de nuestras vidas. Por ello, permanentemente, se impone revisar, volver a pensar, descartar, inventar, por poner algunas palabras y nombrar parte de lo que nos encontramos haciendo en contextos en los cuales, como venimos diciendo nada es obvio, nada va de suyo. Veamos algunos ejemplos:

No es obvio organizar el sistema educativo de cara a los indicadores epidemiológicos, menos obvio hablar de ellos como ahora lo hacemos diariamente.

No es obvio no ir a la escuela, o ir de un modo alternado, en grupos más pequeños, menos obvio operar con criterios de distanciamiento, aislamiento, burbujas como ahora lo hacemos.

No es obvio planificar la enseñanza combinando presencialidad y virtualidad, con modelos múltiples respecto de los modos de organización de los espacios y los tiempos materiales.

No es obvio sabernos otrxs en lo que era habitual y encontrarnos con otrxs en parte desconocidxs, más allá del intento, por momentos desmesurado, de volver a lo habitual. ¿Qué sabemos de Ixs niñxs, Ixs jóvenes, las familias? ¿cuánto podemos entender lo que significa para cada unx atravesar las situaciones actuales? son preguntas que nos hacemos más de una vez.

No es obvio nada de lo que vivimos al punto tal que, como dijo Nancy (2020) para ilustrar el trastocamiento de algunos sentidos y construcciones, "experimentamos el aislamiento como una privación, mientras que es una protección" (s/p). 
Revista de la Escuela de Ciencias de la Educación. 2022, Año 18 1(17). 1-17 Enero a junio. Nicastro, S. Las instituciones y las organizaciones educativas como objeto de análisis y producción de conocimiento situado. Notas para pensar la formación.

Ahora bien, si volvemos a algunos espacios de formación, asesoramiento y/o coordinación nos encontramos con situaciones en las cuales es necesario insistir con la pregunta acerca de lo obvio, lo esperable, lo supuestamente conocido, lo que va de suyo, lo que se automatiza.

Por ejemplo: por qué asociar el ocupar un rol con contar con los saberes necesarios para abordar su campo de intervención. Por qué dar por hecho que, con lo conocido o transitado en los diferentes recorridos profesionales, al llegar a determinado rol se entiende y se puede abordar lo que allí ocurre. Si así fuera, va de suyo:

- que el coordinador de esta escuela entienda lo que sucede y tome decisiones en esa línea, más allá de su antigüedad en el cargo, su trayectoria, las tradiciones respecto de ese rol en esta organización, la cultura institucional y los laberintos a atravesar respecto a la dinámica de poder, etc.

- Que aquella estudiante que realiza una observación de clase entienda lo que allí ocurre, como si la técnica pudiera atrapar lo que sucede y entonces dar cuenta de lo que acontece.

- Que el asesor/orientador que realiza el seguimiento de Ixs niñxs a través de una plataforma mute sin más, sus prácticas habituales de seguimiento de las clases presenciales a las virtuales.

¿Por qué suponer tantas cuestiones como si se tratara de verdades de hecho? Discutir lo obvio, el va de suyo y nuestras posiciones, implica reconocer que contamos con algunos modos de leer la realidad que colaboran para entenderla y otros que no, por lo cual, en estos tiempos alterados, se impone interrumpir algunas prácticas habituales, algunas suposiciones corrientes. Algo así como advertir nuestro apego a algunas explicaciones difíciles de abandonar ligadas más, a constatar lo que ya se sabe que, a preguntarse por lo que no.

También como si se tratara de una mirada obsecuente con sus propias reglas de modo tal que, en línea con Castoriadis (1999), el imaginario singular y los procesos de socialización se inscriben en procesos que se repiten de modo de sostener criterios únicos e impuestos.

La experiencia y reflexión de la protagonista de la novela La dependienta de Murata (2020) es un buen ejemplo de estas ideas, cuando dice "la tienda disponía de un manual impecable y me desenvolvía muy bien como dependienta, pero no tenía ni la menor idea de cómo ser una persona normal en un lugar sin manual de instrucciones" (p.115).

Por todo esto, insistimos en la necesidad de pensar en nuestra posición, implicada y comprometida -aunque no necesariamente siempre de forma consciente- $y$ en la realidad que vivimos ya que como sostiene Ardoino (2005) "la implicación es del orden de lo opaco y no de lo transparente" (p.22).

Ahora bien, vale hacer una aclaración. Decir "yo estoy implicado", "él no está comprometido", "la docente está implicada pero la familia no", son expresiones habituales que se utilizan para describir la relación de cada unx con 
Revista de la Escuela de Ciencias de la Educación. 2022, Año 18 1(17). 1-17 Enero a junio. Nicastro, S. Las instituciones y las organizaciones educativas como objeto de análisis y producción de conocimiento situado. Notas para pensar la formación.

el trabajo, sin embargo, no necesariamente, hacen lugar a la problematización de nuestras posiciones. Como explica Lourau (1991), están más ligadas a un uso o un modo de pensar la implicación como un formulismo o como el resultado de la buena voluntad de cada unx con su trabajo. Cuando este es así, pueden enmascararse juicios de valor sobre unx mismo y sobre Ixs otrxs ligados a un supuesto deber ser de carácter casi religioso que se escurre y termina perfilando las expectativas sobre cada unx. Entonces, el estar comprometidx e implicadx lejos de dar cuenta de los rasgos de la posición de cada sujeto y su relación con la realidad y con el trabajo, se convierte en la evidencia de algo que se mide, se valora, se evalúa ${ }^{1}$.

Como dijimos más arriba, las ideas de transparencia, verdad, objetividad se sostienen en algunas concepciones respecto del sujeto y el conocimiento que, este modo de entender la posición y la implicación, discute. No se trata de un sujeto separado, independiente, prescindente, ni de un conocimiento que se produce por sí mismo bajo las reglas de una supuesta racionalidad ideal.

Para profundizar estas ideas nos vamos a referir a tres cuestiones. Una, ligada a la relación entre la posición, la implicación y los supuestos de neutralidad y objetividad. Otra, que apunta a la relación entre la posición, la implicación y los vínculos con Ixs otrxs. La última se refiere al trabajo sobre la implicación como un proceso inacabado.

\section{De posiciones implicadas y la neutralidad como supuesto}

En más de un caso las ideas de posición e implicación se relacionan con una supuesta neutralidad, en el sentido de no involucrarse en las situaciones, mantenerse a distancia de ellas y, por lo tanto, guardando cierta posición de objetividad. Si bien son numerosas las razones que se han planteado una y otra vez a fin de cuestionar esta conjetura, es una idea que insiste en más de un caso, en apelación al deber ser y a un registro ligado a la moral.

Tal como lo demostró Barbier (1977) en el terreno de las ciencias sociales, hablar de objetividad requiere, entre otras cuestiones, tener en cuenta el análisis de la propia subjetividad. En esta línea, es importante advertir que, en algunas oportunidades, sobrevive como creencia la idea de que la reflexión sobre la implicación puede llevar a controlar los efectos de la biografía y la trayectoria educativa, las marcas de la filiación, la memoria activa, como si fuera posible desprenderse de las huellas que esas experiencias producen. De este modo, alcanzar aquella neutralidad y objetividad se entiende viable, esperable, deseable, como una condición que regula las relaciones entre unxs y otrxs, con los objetos de trabajo y con el colectivo trabajador.

\footnotetext{
${ }^{1}$ Esto supone un desvío porque, como señala Lourau (1991), la idea de implicación se deriva de la discusión acerca de los fenómenos de la contratransferencia propia del psicoanálisis para ser pensada en las ciencias sociales. Es por ello que este autor se referirá a la idea sobreimplicación para marcar algunas diferencias y no perder de vista el registro político de la cuestión.
} 
Revista de la Escuela de Ciencias de la Educación. 2022, Año 18 1(17). 1-17 Enero a junio. Nicastro, S. Las instituciones y las organizaciones educativas como objeto de análisis y producción de conocimiento situado. Notas para pensar la formación.

Vale preguntarnos cómo es posible sostener esta posición con respecto a la implicación y la neutralidad, cuando en variados contextos, desde diferentes producciones y perspectivas, se insiste en reponer la dimensión política del trabajo de educar, las intencionalidades siempre en juego, las dinámicas controversiales que nos reúnen. Seguramente en más de un caso, aquél supuesto se sostiene porque se le adjudica a las ideas de encuadre, método, protocolo, guía una acción mágica. Instrumentos todos necesarios, pero no suficientes, si se leen por fuera de determinada teoría del conocimiento y paradigma epistemológico que orienten la construcción de dispositivos de análisis. Allí la lógica en juego, lejos de implicar estructuración y fijación, opera desde la atención de lo singular, con abordajes dinámicos y la revisión permanente de criterios. Parafraseando a Zambrano (2000) diríamos miradas animadas por la búsqueda y no animadas por la cacería, miradas sostenidas en la implicación con lo situado, formando parte y haciendo de ello objeto de reflexión constante.

Podemos ilustrar lo que venimos diciendo con situaciones que se desarrollan en espacios de formación, asesoramiento, coordinación. Seguramente si hacemos memoria nos encontramos en algunas escenas, portando nuestra historia, juicios y prejuicios, concepciones tácitas, expectativas de la formación, marcas de la cultura profesional -objeto de pasaje entre unxs y otrxs en los espacios de formación- entre tantas otras. Estamos allí con otrxs, haciendo de ellas relatos. Estamos allí y esa relación se transforma, de modo permanente, en un espacio de construcción inédito. Estamos allí, en un "entre" que podríamos decir no tiene dueñx, no es de unxs ni de otrxs, ensambla el acercamiento y la separación, la extrañeza con la familiaridad, la confianza y la desconfianza.

Es por eso, que sin desconocer que -en simultáneo a que cada unx se encuentra envuelto, involucrado, comprometido, implicado en esa escena- se intenta construir y sostener cierta distancia necesaria a los fines de la configuración de las diferentes posiciones y sus relaciones. Ahora bien, esa distancia no es automática, ni se da de un modo natural, supone un trabajo sostenido sobre la implicación y desde allí invita al reconocimiento de ciertos lazos, pertenencias, compromisos culturales y simbólicos. Dirá Enriquez (2000)

lo que les pasa a otros tiene resonancia en mí, es capaz de hacerme vibrar, y, por lo menos, de interesarme, en el sentido fuerte del término, es decir, ponerme en movimiento, obligarme a un trabajo mental y a una interrogación sobre mí mismo. Estoy, por ende, totalmente presente en cada momento de la intervención, acepto la conmoción provocada por el reencuentro con el prójimo, no trato de ponerme un caparazón para protegerme (p.7).

Cuando algo de esto no ocurre, cuando miramos a unx maestrx suponiendo objetividad, cuando escuchamos a Ixs estudiantes y suponemos neutralidad, cuando nos acercamos a una escena educativa y suponemos distancia, es probable como dice Legendre (2008) que algo de la curiosidad quede "hipotecada" bajo presupuestos totalizantes que paradójicamente, lejos de favorecer el acercamiento, la exploración, la pregunta y el interés por 
Revista de la Escuela de Ciencias de la Educación. 2022, Año 18 1(17). 1-17 Enero a junio. Nicastro, S. Las instituciones y las organizaciones educativas como objeto de análisis y producción de conocimiento situado. Notas para pensar la formación.

entender, fabrican desconocimiento y fortalecen lo instituido, lo establecido, lo ya sabido.

\section{La implicación siempre supone a Ixs otrxs}

La segunda cuestión sobre la que nos interesa llamar la atención con respecto a la idea de posición y de implicación, tiene que ver con el planteo de Ardoino (2005), cuando reconoce que se trata de un trabajo que incluye a otrxs.

El trabajo sobre las implicaciones no podrá realizarse desde una perspectiva de claridad creciente, de higiene, sino que ella necesita de la referencia a terceros, pasa por otras miradas, la acción mediadora de otros, necesita de "alteraciones" (p.22).

En este sentido podemos hacer de esa relación un punto de reparo para preguntarnos acerca de quiénes y cómo se encuentran y, sobre todo, qué ve cada unx en Ix otrx. Como el estribillo de la conocida canción que dice "¿Qué ves? ¿Qué ves cuando me ves? como interrogación que convoca a cada unx de los que participan de ese encuentro.

Ahora bien, no respondamos apresuradamente, porque no hay premura de respuesta e intentemos hacer evidente el espacio que se construye entre unxs y otrxs, que, si bien no existe por fuera ellxs y no le pertenece a ninguna de las partes, Ixs sostiene en una posición que se construye, configura y está inscripta en la relación entre diferentes contextos institucionales, sociales, políticos, culturales, organizacionales, grupales, subjetivos.

Es decir que estamos "en medio de" como señaló alguna vez Lewkowicz (2003). En medio de este tiempo, en medio de esta historia, en medio de esta cultura escolar, en medio de estas tradiciones situadas, en medio de estas relaciones interpersonales, laborales o de formación. En medio de, supone simultaneidad, entrecruzamientos, contemporaneidad, desplazamientos, idas y vueltas, significa habitar el mientras tanto. Es decir que nos encontramos en la misma línea de lo que hace un rato reconocíamos cuando dijimos "estamos allí".

Para ilustrar esta idea apelamos a la metáfora que Gornick (2020) presenta en su novela "Mirarse de frente" cuando se refiere al "Síndrome de la Respuesta Aproximada", como eso que le pasa, en sus palabras, a la "gente como nosotros". En su caso se trata de un grupo de profesorxs, que viven aisladxs en unas conversaciones en las que redundan las frases hechas y donde no hay mucho para decir. Se encuentran en medio de unxs y otrxs y lidian con todo lo que esto implica, dando por supuesto el entendimiento cuando en realidad cada unx va por su camino sin interés en el resto. Pero claro, como colectivo de esto no se habla.

Retomando a Puget (1988) estar "en medio de" puede relacionarse con lo que esta autora nombró como "mundos superpuestos", en el sentido que lo que se comparte aplaca la curiosidad, porque damos por sabido, porque damos por obvio, porque en el encuentro con otrxs nos reconocemos inmersos en lo mismo.

Por ejemplo, ustedes y nosotrxs sabemos de qué se trata lo que estamos atravesando y decidimos que no hace falta explicar de lo que trabajamos, ni los 
Revista de la Escuela de Ciencias de la Educación. 2022, Año 18 1(17). 1-17 Enero a junio. Nicastro, S. Las instituciones y las organizaciones educativas como objeto de análisis y producción de conocimiento situado. Notas para pensar la formación.

supuestos, encuadres, concepciones que portamos, menos aún hablar de pandemia, burbuja, sistema bimodal. Lo mismo en una escena de formación, donde las experiencias y situaciones que atraviesan Ixs formadorxs y Ixs estudiantes se entienden como comunes. Para usar las palabras de esta autora, el riesgo que se corre en estos casos es "una inundación en el encuadre". ¿Qué quiere expresar de este modo? Que el efecto analizador, lo que provoca, lo que devela, lo que interpela en cada una de las situaciones, queda constreñido por el supuesto saber de qué se trata. Así se trastocan los dispositivos de análisis y se favorece la automatización, la normalización y la repetición. A veces, al punto que la pregunta situada, la que hace visible la diferencia, la que intenta dar la palabra para hacer presencia en una voz, la que da lugar a lo que hace borde y a lo que no tiene palabras, se difiere o forma parte de lo que se entiende como secundario.

El segundo rasgo a señalar respecto de la relación con otrxs está ligado a la idea de expertiz. Como dijimos, al hablar de posición, aludimos tanto a un lugar que se ocupa en determinado espacio y tiempo institucional, como a los sentidos y definiciones que portamos y construimos con otrxs para decir de qué trabajamos, cuál es nuestra tarea, de qué trata, qué se espera, etc. Desde aquí es posible observar que en algunas oportunidades ocupar determinadas posiciones en el marco de la formación, la coordinación o el asesoramiento, queda asociado rápidamente a un lugar de expertiz. A veces, esto se debe a las expectativas, tanto propias como ajenas, que pesan sobre algunas posiciones, de tal modo que la fuerza de lo que se espera prefigura el lugar. En otros casos, por determinadas reglas, arraigadas en las culturas institucionales y profesionales, que ordenan las relaciones, las jerarquías, los intercambios entre roles y funciones, estipulando, de antemano, el lugar de la expertiz.

De cara a que el encuentro con otrxs, como referentes terceros, se transforme en una oportunidad para el análisis de la implicación, es esperable problematizar profundamente ese lugar y tal como lo señala Cornu (2017), hacer de él un "caminar en compañía".

El último rasgo a señalar tiene que ver con relacionar el trabajo sobre las implicaciones con el trabajo sobre el pensamiento que siguiendo a Käes (2005), también es un trabajo con otrxs. Tal como afirma este autor "no se puede pensar solo y al mismo tiempo no se puede pensar sino por separado" (s/p). Es decir, que se trata de una relación de diferenciación, de modo de interrumpir repeticiones o intentos de reflotar mandatos, y a la vez de filiación, con nuestrxs antecesores, con quienes nos reunimos al hacer memoria, también con Ixs contemporáneos, en esa distancia que nos acerca y nos sostiene extranjerxs al mismo tiempo.

A partir de lo dicho es evidente que pensar la posición y la implicación en la relación con los otrxs es parte del trabajo de indagación, exploración y análisis, que llevamos adelante en espacios de formación, asesoramiento y coordinación, bajo el supuesto que en el intercambio y la argumentación colectiva surgirán otros modos de entender, de interpretar, de recortar, de problematizar aquello que se define como objeto de estudio y de intervención. Todo esto en tensión 
Revista de la Escuela de Ciencias de la Educación. 2022, Año 18 1(17). 1-17 Enero a junio. Nicastro, S. Las instituciones y las organizaciones educativas como objeto de análisis y producción de conocimiento situado. Notas para pensar la formación.

permanente, en una dinámica que tiene de disputa de sentidos, de negociación, donde los consensos, al decir de Mouffe (2007) son siempre controversiales.

\section{El análisis de las posiciones implicadas desafía lugares prefijados}

La última cuestión tiene que ver con pensar el trabajo sobre la implicación como un proceso inacabado, que no se agota en un momento especialmente dedicado a ese tema. Es decir que no se requiere de un lugar preferencial en un programa o en una jornada de trabajo para luego seguir con lo que hace agenda. No se ciñe a un paso, a una etapa, no es una cuestión que se resuelve de una vez y para siempre. Insiste, apela, presiona, es una invitación a interrogarnos. Algo así como poner a trabajar estas cuestiones al servicio de la elucidación y el entendimiento. En palabras de Manero (2020) "el análisis de las implicaciones no es un añadido, un plus más o menos autobiográfico y reflexivo al final de un reporte o de un artículo de investigación" (p.298).

El análisis de la implicación no tiene que ver con compartir emociones, impactos, impresiones, resonancias, supuestos, etc. como si solo se tratara de un momento de intercambio que una vez finalizado no tiene efectos. En realidad, conlleva entender de qué modo estas cuestiones nos configuran en las diferentes posiciones institucionales e intervienen en los procesos de construcción de conocimiento.

Por todo esto decimos que nuestro interés en reflexionar sobre la implicación tiene que ver con avanzar en un tipo de análisis que tenga en cuenta sus efectos, su cualidad de andamiaje, como si nos hiciéramos la pregunta: ¿cómo nos trabaja?, ¿cómo nos atraviesa? De lo contrario se corre el riesgo de banalizar extremadamente este tema y suponer que poner de manifiesto sentimientos, sensaciones, opiniones, impresiones, es suficiente para que la implicación aporte al análisis que se realiza, como si se tratara de cuestiones siempre conscientes, atrapables, que se nombran y entonces se transforman.

Como dijimos anteriormente, nos apoyamos en un supuesto desde el cual el análisis no tiene que ver con pasar de lo opaco a lo transparente, de lo invisible a lo visible y de lo no dicho a lo dicho. Nada más lejano en este momento.

Entendemos que estas cuestiones son claves porque llaman la atención sobre la necesidad de hacer foco en cada una de nuestras posiciones y también en nuestras apreciaciones, explicaciones, efectos de resonancia. Como ya dijimos no se trata de entender, saber qué hacer, teorizar, explicar lo que nos pasa de un modo acabado, aunque para muchos sería lo esperable. En realidad, más que encontrar "la" teoría, "la" categoría, "la" hipótesis, "la" explicación que aporte seguridad, nos interesa abandonar cualquier ilusión de este tipo. No será lo atrapable y controlable lo que nos provoca sino habilitar el pensamiento, lo que implica y nos implica, en los espacios y los tiempos presentes, pasados y por venir. Algo así como mantenernos en la tensión entre lo posible y lo pensable, tensión, motor, inacabada, constante.

Poco saber no equivale a saber poco, alude a saber lo ilimitado, lo inalcanzable, lo inconcebible del saber clínico. Estar en posición de poco saber previene omnipotencias, 
Revista de la Escuela de Ciencias de la Educación. 2022, Año 18 1(17). 1-17 Enero a junio. Nicastro, S. Las instituciones y las organizaciones educativas como objeto de análisis y producción de conocimiento situado. Notas para pensar la formación.

soberbias, individualismos profesionales.

(Percia, 2020, s/p)

\section{CONCLUSIÓN}

En el lugar de formadorxs, atravesadxs, conmovidxs y, una vez más, ante escenarios en los cuales la incertidumbre, por momentos, opera como clausura, reconocemos imprescindible el abordaje de las instituciones y las organizaciones educativas haciendo de ellas un objeto de análisis y producción de conocimiento. Para ello será necesario el trabajo permanente sobre nuestras posiciones implicadas, como oportunidad de pensar a otrxs y con otrxs, no como una obligación, ni como un mandato, menos aún como una operación que busque tranquilizar y normalizar. Sí en todo caso, como espacio de problematización, de interrogación, de interrupción que puede asociarse a Nancy, J .L. (2020) cuando alude a la idea de Derrida de "destinerrancia" como "un destino para errar. Errar no es extraviarse, lo cual supone que se han abandonado las sendas trazadas. No es ir descaminado, sino recorrer un espacio sin rutas ni puntos de referencia" (p.52).

Por qué no pensar que el errar sin extraviarse circula en el trabajo de análisis de nuestras posiciones, de nuestra implicación y hace de base y andamiaje a la puesta en acción de los propósitos que nos planteamos como formadorxs: cuando nos dejamos interrumpir, nos dejamos alterar, a pesar de la incertidumbre, la desazón, la curiosidad, la incomodidad que nos atraviesan, sostenidxs, por decirlo de alguna manera, en espacios colectivos de pensamiento. Lo que nos reúne y nos separa al mismo tiempo, lo que hace común, anida con otrxs y entre otrxs, en la controversia del encuentro en el campo de lo público.

Esto ocurre en numerosas experiencias situadas de formación, en la intimidad del pasar la posta, de transmitir y de producir, donde se comparten y se ofrecen, se negocian y se disputan detalles, gestos, trucos, coartadas. Allí ocurre algo intangible que deja huella, un proceso que no cesa, que siempre tiene resto, que supone miramiento, y al decir de Cifalli (2012), de "tacto, prudencia y humildad" (s/p), condiciones ineludibles en el trabajo de formar y de formarse.

\section{REFERENCIAS}

Ardoino, J. (1993). El análisis multirreferencial. Revista de Educación Superior, 22(87)

Ardoino, J. (1981). El imaginario del cambio y el cambio del imaginario en F. Guattari y otros La intervención institucional. Folios.

Ardoino, J. (2005). Complejidad y formación. Facultad de Filosofía y Letras, Ediciones Novedades Educativas.

Barbier, R. (1977). La recherche-action dan's institution educative. Gauthier Villars Bordas.

Bozzolo, R.; Bonnano, O. y L'Hoste, M. (2008). El oficio de intervenir: Políticas de subjetivación en grupos e instituciones. Edit. Biblos. 
Revista de la Escuela de Ciencias de la Educación. 2022, Año 18 1(17). 1-17 Enero a junio. Nicastro, S. Las instituciones y las organizaciones educativas como objeto de análisis y producción de conocimiento situado. Notas para pensar la formación.

Castoriadis, C. (1999). La institución imaginaria de la sociedad. Tomo 1. Tusquets.

Cifalli, M. (2012). Referencias breves. Cuadernos de pedagogía No. 427.

Cornu, L. (2017). Acompañar el oficio de hacer humanidad en Frigerio, G.; Korinfeld, D. y Rodríguez, C. Trabajar en instituciones: Ios oficios del lazo. Noveduc.

De Brasi, J. C. (2013). Ensayo sobre el pensamiento sutil: La cuestión de la casualidad. La casualidad en cuestión. Ediciones La cebra.

Dejours, C. (2013). Trabajo vivo: Trabajo y emancipación. Tomo 2. Topia Editorial.

Derrida J. y Roudinesco, E. (2003). Y mañana qué... Fondo de Cultura Económica.

De Sousa Santos, B. (2020). La cruel pedagogía del virus. CLACSO. http://biblioteca.clacso.edu.ar/clacso/se/20200430083046/La-cruelpedagogia-del-virus.pdf.

Dufourmantelle, A. (2019). El elogio del riesgo. Nocturna editora.

Enriquez, E. (2000). Implication et distance. Les cahiers de l'implication. Revue d'analyse institutionnelle 3 L'intervention. Université

Enriquez, E. (2003). El análisis clínico en ciencias humanas en J. Barceló (Comp.), Sociología Clínica. Universidad de la República.

Fernández, A.M., et. al. (2014). La indagación de las Implicaciones: un aporte metodológico en el campo de problemas de la subjetividad. Revista Sujeto, Subjetividad y Cultura, (7) 5-205.

Garay, L. (1996). La cuestión institucional de la educación y las escuelas: conceptos y reflexiones en I. Butelman, (Comp.) Pensando las instituciones. Sobre teorías y prácticas en educación. Paidós.

Gornik, V. (2020). Mirarse de frente. Editorial Sexto Piso.

Jackson, P. (1999). Enseñanzas implícitas. Amorrortu.

Käes, R. (1989). La institución y las instituciones. Paidós.

Käes, R. (2005). La palabra y el vínculo. Amorrortu.

Lapassade, G. (1979). El analizador y el analista. Gedisa.

Legendre, P. (2008). El Tajo: Discurso a jóvenes estudiantes sobre la ciencia y la ignorancia. Amorrortu.

Lewkowicz, I. (2003). Conceptualización de catástrofe social. Límites y encrucijadas en D. Waisbrot; M. Wikinski; C. Rolfo; d. Slucki y S. Toporosi Clínica psicoanalítica antes las catástrofes sociales. La experiencia argentina. Paidós.

Lourau, R. (1975). Análisis Institucional. Amorrortu.

Lourau, R. y otros (1979). Análisis institucional y socioanálisis. Editorial Nueva Imagen.

Lourau, R. (12 de noviembre de 1991). Implicación y sobreimplicación. Conferencia. 2do. Congreso El espacio institucional. Buenos Aires, Argentina.

Manero Brito, R. (2020). Cuestiones epistémicas derivadas del análisis de las implicaciones en la psicología social. Revista Enseñanza e Investigación en Psicología. 2(2) CNEIP

Mouffe, CH. (2007). En torno a lo político. Fondo de Cultura Económica 
Revista de la Escuela de Ciencias de la Educación. 2022, Año 18 1(17). 1-17 Enero a junio. Nicastro, S. Las instituciones y las organizaciones educativas como objeto de análisis y producción de conocimiento situado. Notas para pensar la formación.

Murata, S. (2020). La dependienta. Duomo Nefelibata Ediciones.

Nancy, J. L. (2020). Un virus demasiado humano. Palinodia.

Nicastro, S. (2017). Trabajar en la escuela: Análisis de prácticas y de experiencias de formación. Homo Sapiens.

Oury, J. (2020). Lo colectivo. Xoroi Ediciones.

Percia, M. (2020). Esquirlas, pliegues de la peste. Ediciones La cebra.

Puget, J. y Käes, R. (comps.) (1988). Violencia de estado y psicoanálisis. Centro Editor de América Latina.

Ulloa, F. (1995). Novela clínica psicoanalítica: Historial de una práctica. Paidós. Zambrano, M. (2000). Hacia un saber sobre el alma. Alianza. 